\title{
FRONTEIRA, CORREDORES DE EXPORTAÇÃO E REDE URBANA NA AMAZÔNIA ORIENTAL BRASILEIRA
}

\author{
MAURÍLIO DE ABREU MONTEIRO \\ Universidade Federal do Pará \\ MARIA CÉLIA NUNES COELHO \\ Universidade Federal do Rio de Janeiro \\ ESTÊVÃO JOSÉ DA SILVA BARBOSA \\ Universidade de São Paulo
}

\section{Introdução}

Na Amazônia, a incorporação de novos espaços aos circuitos do capital, na segunda metade do século passado, esteve associada, em grande medida, a processos de apropriação de recursos naturais mediante sua conversão em mercadorias. A mercantilização de recursos naturais implica, necessariamente, a alteração das formas e dos conteúdos do espaço, produzindo impactos e alterações irreversíveis. O significado dessas alterações suscita um debate teórico acerca da qualidade dos processos de desenvolvimento desencadeados em regiões abundantes em recursos naturais, que tem como marcos os trabalhos de Albion (1926) e Innis (1933) e recebeu crescente atenção a partir dos anos 1970 do século XX. Parte dessas reflexões volta-se para a análise das alterações decorrentes da valorização de minérios, entendida como a agregação de valor por meio de trabalho e conversão de recursos minerais em mercadorias (Warren, 1973; Bosson e Benson, 1977; Spooner, 1981; Giraud, 1983; Bomsel et al, 1990; Bahram, Bunker e O'hearn, 1994; Clark e Clark, 1999; Bridge, 2004; Bebbington et al, 2008).

Nesse contexto, a valorização de minérios energéticos e não energéticos da Amazônia impulsionou transformações que, acompanhando a expansão das economias de escala e do sistema econômico capitalista global (Bunker, 2004), alteraram estruturas sociais e espaciais em diversas áreas da região. Na Amazônia brasileira, a porção oriental foi a mais 
afetada (Bunker, 1985; Monteiro, 2005), por nela se localizar a quase totalidade das infraestruturas necessárias à explotação de minérios e à transformação industrial de parcela deles em produtos semielaborados alumina, alumínio e ferro-gusa -, destinados, em sua quase totalidade, à exportação.

No presente texto, discute-se a formação de corredores que viabilizam a exportação dessas mercadorias e os impactos que eles provocaram nas configurações urbano-regionais. A análise apoia-se na noção de fronteira, que permite entendê-los, espacial e temporalmente, como integrantes de zonas de expansão de sistemas produtivos que comportam frentes distintas. Conforme Browder e Godfrey (1997), na fronteira amazônica, opõem-se e complementam-se frentes de recursos e frentes de povoamento cujos efeitos sobre o uso de recursos, o ambiente, o território e a urbanização são diferenciados.

$\mathrm{Na}$ primeira parte do texto, é feita a indicação das contribuições teóricas que permitem reunir elementos para que os processos de mudança espacial na Amazônia sejam analisados como vinculados à lógica de fronteira. Na segunda, a formação de corredores de exportação na Amazônia oriental é examinada como fenômeno que se vincula à fronteira amazônica, ligando-se, temporal e espacialmente, às dinâmicas de valorização de recursos naturais, à geração de superávits na balança comercial e à economia-mundo. Na terceira e última parte, discutem-se as mudanças - e também as permanências - na geografia desses corredores, como consequência das transformações socioespaciais recentes na região. Relacionam-se analiticamente a importância e a extensão da mercantilização de recursos minerais nas mudanças e reconfigurações urbanas da região na segunda metade do século passado com dinâmicas mais gerais da fronteira.

\section{Elementos teóricos e empíricos para a análise da Amazônia como fronteira}

A noção de fronteira tem papel central nas análises sociológicas, antropológicas, políticas, econômicas e geográficas acerca das mudanças que ocorreram no território brasileiro ao longo do século XX (Monbeig, 1952; Godfrey, 1979; Foweraker, 1981; Sawyer, 1984; Cleary, 1993; Martins, 1996; Schneider, 1995). 
O termo fronteira possui um sentido polissêmico nos campos da geografia, da história, da economia política e das ciências sociais. Em termos gerais, identificam-se duas acepções principais: a de limite, frente ou zona de concorrência e complementaridade entre territórios ou sistemas de natureza diversa; e a de limite, frente ou zona de expansão que desloca ou redefine o modo de produção capitalista no tempo e no espaço (Badie, 1995; Courlet, 1996). Nessa segunda acepção, adota-se a noção de fronteira como avanço de frentes pioneiras sobre terras livres, incorporadas às estruturas de reprodução campesina e gradando para a lógica de mercado, ideia fundada no trabalho de Turner ([1920], 1996) sobre a marcha da ocupação do oeste dos Estados Unidos.

Nas dinâmicas de expansão, o contato entre sistemas distintos de apropriação de recursos naturais estabelece-se a partir da diversidade de agentes. Alguns deles tratam esses recursos naturais como valor de uso e outros os convertem em mercadoria, ou seja, imputam-lhes também a condição de valor de troca. Assim, o lugar (frente ou zona) do avanço é, simultaneamente, o espaço do estranhamento, da contradição, da concorrência, do embate e de complementaridades nos planos econômico, político e cultural (Martins, 1996), com efeitos nas temporalidades e nas configurações geográficas, visto que o espaço é, dialeticamente, base material e social de dinâmicas com diferentes ritmos e formas de uso do tempo (Soja, 1989).

Descarta-se, por conseguinte, a ideia de terra "livre" ou "inexplorada" contida na concepção de frente pioneira, visto que o espaço que se redefine é geográfico também porque herdou as estruturas do passado histórico. Não se pode, portanto, desprezar o papel das estruturas socioespaciais preexistentes. Surge aí uma dialética entre as formasconteúdos novas e as antigas, porém estas são frágeis demais para resistir ao avanço das primeiras, dada a intensidade das forças que geram as fronteiras, em especial as do capital (Becker, 1982, 1990; Bunker, 1985).

Desse modo, considera-se, em primeiro lugar, o sentido de zona de expansão contido no termo fronteira, o que permite discutir dinâmicas no tempo e no espaço. Segundo, admite-se que a fronteira abrange uma diversidade de fatores e agentes que se complementam e/ou se contradizem, não sendo possível, portanto, pensá-la a partir de um único agente ou fator. A respeito do primeiro aspecto, faz-se necessário definir o 
tempo inicial e o tempo final da fronteira, uma vez que, se ela é mutável, forma-se e tende a desaparecer ou a se deslocar, o que vale também para localizá-la e discuti-la espacialmente. Analisa-se a espacialidade amazônica localizando-se fatores que, partindo de um quadro com tendências gerais para uma região, estabelecem-se em um determinado momento e depois vão sumindo, tornando-se residuais, passando a ser ou já surgindo como eventos de escala local.

Assim, está-se diante de uma análise de mudanças geográficas. No caso amazônico, ${ }^{1}$ destacam-se os conflitos fundiários (Hébette, 2004), a alteridade sociocultural e de temporalidades (Martins, 1975), o embate e as associações entre formas pré-capitalistas ou mercantis e as do capitalismo financeiro e da produção industrial (Bunker, 1985), o estado dos vetores de expansão e de ocupação territorial, e a estabilidade dos sistemas ambientais e dos modos de valorização do solo e dos recursos naturais (Becker, 2004; Cleary, 1993; Coelho, 1997). Esses fatores têm importância variada nos tempos de formação e nas temporalidades das fronteiras. ${ }^{2}$

Assim sendo, à medida que os conflitos de ordem diversa se reduzem e as novas estruturas socioespaciais se consolidam, as fronteiras deixam de existir, dando lugar a geografias mais estáveis. As fronteiras contemporâneas, em especial, tendem a ser mais complexas e

Todos os autores citados a seguir enfatizaram a Amazônia brasileira. No entanto, as dinâmicas de fronteira ocorridas em outros países da Pan-Amazônia ensejaram, igualmente, farta literatura de autores nacionais ou estrangeiros. Como exemplos, podem ser citados os casos da Colômbia em Gómez (1999) e o do Equador em Ryder e Brown (2000).

2 Para a realidade em foco, estudos mais recentes demonstram que, nos espaços que sofreram maiores transformações entre os anos 1950 e 1980, as dinâmicas típicas de fronteira já cessaram ou perderam intensidade, sobretudo ao longo dos grandes eixos viários abertos na porção oriental e meridional da Amazônia brasileira. Cleary (1993) fornece exemplos de Rondônia e do Sudeste Paraense, afirmando que, desde o final dos anos 1980, essas áreas entraram em um estágio de "pós-fronteira". Veríssimo et al. (1992), ao enfatizar aspectos relativos ao quadro de apropriação da terra e dos recursos naturais, caracterizaram a área de Paragominas como uma "velha fronteira". De outro modo, na Amazônia ocidental, nas zonas de limite com os países vizinhos e em áreas de localização intermediária entre os eixos abertos em décadas passadas, existem espaços com situação de fronteira ativa ou potencial (Becker, 2004, 2008; Laurance et al., 2001; Théry, 2002). 
multifacetadas quando comparadas às suas congêneres do século XIX e das primeiras décadas do século XX (Becker, 1990).

Sobre a Amazônia brasileira, desde os anos 1980, interpretações passaram a questionar as teorias "clássicas" sobre a fronteira (Cleary, 1993), visto que as estruturas sociais e econômicas nesse espaço eram mais heterogêneas do que se supunha e nem sempre tinham o campesinato como ponto de partida, uma vez que também passaram a ser diretamente implantadas com conteúdos capitalísticos e industriais, como a mineração industrial (Bunker, 1985) e o latifúndio empresarial (Costa, 1993), ou estavam associadas à garimpagem (Mathis, Brito e Brüseke, 1997), às atividades madeireiras (Uhl et al, 1991), à produção de ferro-gusa (Autor 1, 1998), assim como às novas realidades urbanas e rurais (Sawyer, 1984), que se mantinham, e ainda se mantêm em várias situações, com base em formas pré-capitalistas ou mercantis, fortemente baseadas em relações informais.

Portanto, a noção de fronteira ajuda a situar as mudanças regionais no contexto de um espaço que passou por profundas transformações nas últimas décadas. Assim, se a noção de fronteira tem poder heurístico em relação às dinâmicas ocorridas na Amazônia entre as décadas de 1950 e 1990 do século XX, seu uso, entretanto, deve ser feito com precaução para os tempos mais recentes, visto que muitas porções da região já entraram em um estágio de "pós-fronteira" (Cleary, 1993; Théry, 2002; Becker, 2004). Note-se também que a existência de múltiplos fatores e a atuação de muitos atores na fronteira amazônica implica o reconhecimento analítico da complexidade dessa configuração regional, o que não impede a identificação de padrões espaciais. Dessa forma, a despeito do caráter multifacetado da fronteira amazônica, as dinâmicas que nela incidiram na segunda metade do século XX podem ser agrupadas em dois padrões espaciais complementares, que permitem a análise das principais transformações sociais e espaciais:

a) frentes de povoamento, com dinâmicas motivadas por interesses mercantis ou não, voltados à apropriação da terra, principalmente pela agropecuária, e que, não obstante os conflitos entre as frações do capital e destas com o campesinato e populações ditas "tradicionais", motivam uma ocupação mais efetiva e permanente do território; e 
b) frentes de recursos, nas quais as dinâmicas são ensejadas pela apropriação, por meio da extração de recursos naturais (produtos florestais, minérios, animais), cujo potencial, por causa de sua raridade, do sobre-uso ou do manejo não sustentável, esgota-se em alguns anos ou décadas, o que conduz à ocorrência de pulsos econômicos e populacionais (Hébette e Acevedo Marin, 1979; Godfrey, 1982, 1990; Browder e Godfrey, 1997; Ryder e Brown, 2000).

Justamente por isso, e apesar de fortemente urbanizada, essa fronteira possui, nos espaços rurais, um lócus muito relevante de atividades econômicas (Becker, 1990; Corrêa, 1991; Machado, 1999; Trindade Júnior, 2006; Trindade Júnior e Rocha, 2002).

Os corredores de exportação analisados neste artigo foram responsáveis pela manutenção dos superávits na balança comercial brasileira no final da última década do século passado e ainda o são no presente (Figura 1). Trata-se de corredores caracterizados por elevado coeficiente de exportação - uma vez que a valorização de recursos minerais resulta na produção de mercadorias que, ao serem exportadas, implicam ingresso no país de elevadas cifras - e cuja produção, em contrapartida, demanda a importação de insumos relativamente baratos, favorecendo, sobremaneira, a balança comercial.

Assim, o estabelecimento de corredores de exportação na Amazônia brasileira reflete a articulação de três escalas espaciais: na economiamundo, vincula-se à crescente demanda por insumos industriais; na economia nacional, liga-se ao interesse de segmentos hegemônicos na sociedade nacional em ampliar superávits na balança comercial; e, no âmbito regional ou local, conecta-se com a expansão das frentes de recursos da fronteira. 


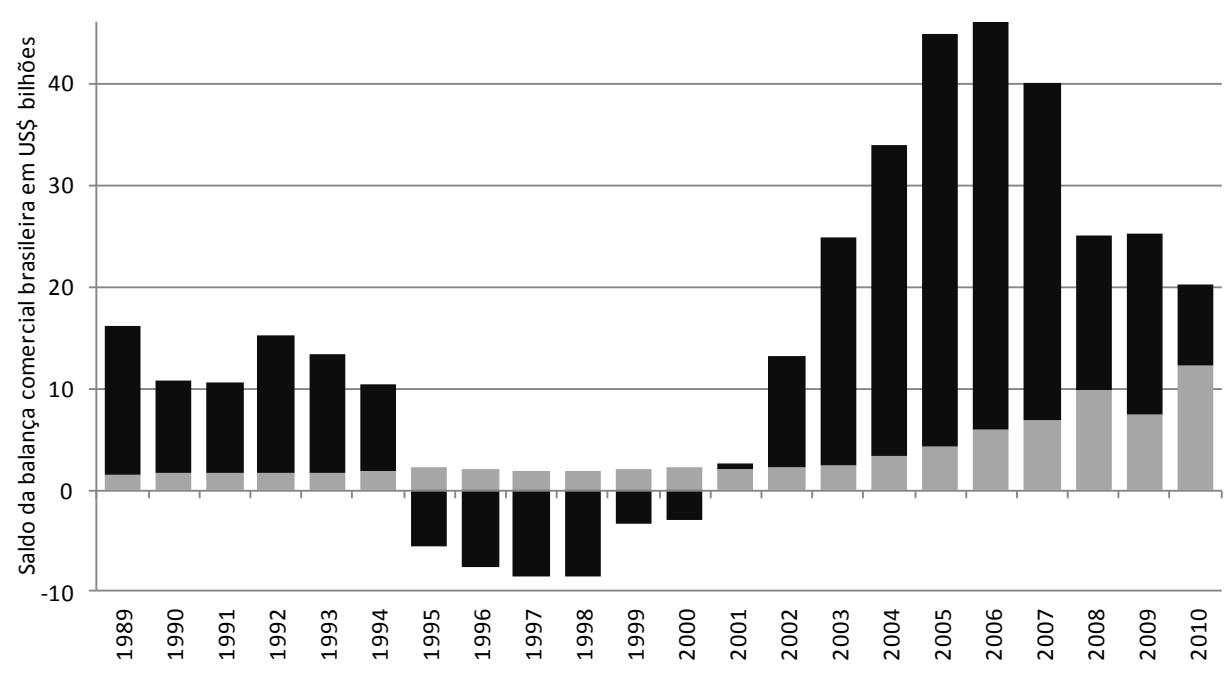

Contribuição das exportações dos corredores para a balança comercial brasileira

Figura 1: Gráfico com participação de produtos minerais exportados pelos portos ou terminais privativos (TP) de Santana (AP), TP de Porto Trombetas (PA), TP Munguba (PA), Vila do Conde (PA), Itaqui/TP Ponta da Madeira (MA) e TP da Alumar (MA) no saldo da balança comercial brasileira.

Fonte: Elaboração dos autores com base em Brasil (2011).

\section{Mineração, corredores de exportação e dinâmicas espaciais}

Durante a Segunda Guerra Mundial, o surto da demanda por produtos siderúrgicos provocou importantes avanços tecnológicos nos sistemas de transporte, assim como na fabricação de ferro e aço, na geografia e nas estruturas econômicas associadas (Valverde, 1989). No pós-guerra, a retomada do crescimento econômico na Europa, na América do Norte e no Japão ampliou a busca por matérias-primas para a indústria siderúrgica e metalúrgica, o que conduziu à realização de vultosos investimentos para a valorização industrial de recursos minerais em grande escala, muitas vezes no âmbito de políticas desenvolvimentistas nas quais Estados nacionais criaram e expandiram firmas estatais ou apoiaram grandes mineradoras.

Constituindo um fator-chave de mudanças do ponto de vista social, econômico e ambiental nas regiões ricas em matérias-primas como a 
Amazônia brasileira, essas práticas foram numerosas em regiões periféricas, com uma fase mais acentuada entre 1950 e 1980 (Furtado, 1976; Giraud, 1983; Bomsel et al, 1990; Bryant e Bailey, 1997), aproximadamente, e outra mais recentes e de novas nuances, sobretudo com a privatização de empresas mineradoras e a alteração do quadro de principais centros consumidores e players do comércio internacional de commodities minerais a partir da segunda metade dos anos 1990, dado o crescimento das economias emergentes, destacando-se a China e a Índia (Clark e Clark, 1999; Bebbington et al, 2008).

Além do crescimento da demanda, favoreceram a expansão daquele comércio os avanços registrados nas tecnologias de explotação e de transportes de minérios. A valorização industrial de recursos minerais, vinculada a frentes de recursos da fronteira amazônica, articula-se, assim, com o aperfeiçoamento das tecnologias de extração, produção e transporte. A combinação desses aspectos abriu caminho para a lavra de minas cada vez mais distantes dos centros industriais e o crescimento da dimensão das minas, o que favoreceu a incorporação de regiões cada vez mais remotas à economia-mundo (Bunker, 2004).

Nesse contexto, a Amazônia oriental brasileira, desde a segunda metade do século XX, foi alvo de interesses que buscaram controlar e valorizar industrialmente os minérios, desencadeando ali mudanças geográficas que refletem novos padrões de relações sociais e com a natureza (Bunker, 1985; Monteiro, 2005). A lavra, o beneficiamento primário e a transformação industrial de minérios, sobretudo de ferro, alumínio, manganês e caulim, ensejaram a constituição de rotas de transporte. Elas estão na origem de eixos que se explicam não só pelas ocorrências geológicas, pelas distâncias, pela topografia, pela distribuição da rede hidrográfica, pela posição dos portos e pela localização das fontes de energia, mas também pelo desenvolvimento de técnicas e de meios de transporte que influem nos processos de definição de corredores de exportação.

${ }^{3}$ Nesse período, o comércio internacional de commodities minerais e o preço delas apresentaram tendência positiva até 1973, quando houve o primeiro "choque do petróleo". Na sequência, assistiu-se ao estabelecimento de uma crise econômica mundial com fortes reflexos nesse comércio, cujo dinamismo manteve-se, principalmente, na cadeia do alumínio, em decorrência de seu papel fundamental na dinâmica industrial japonesa dos anos 1970 e 1980 e na transferência de unidades metalúrgicas para os países em via de desenvolvimento (Giraud, 1983).

${ }^{4}$ Pode-se estabelecer, a esse respeito, um contraponto com a valorização de minérios que ocorria no século XIX e em boa parte do século XX. Brunhes (1920) fornece vários 
A formação de corredores de exportação na Amazônia oriental brasileira deve ser entendida, assim, a partir da articulação de escalas e, por conseguinte, também à luz das já citadas transformações na economiamundo que impulsionaram grandes investimentos no setor mineral em regiões periféricas (Bunker, 1985).

Na Amazônia oriental brasileira, não são somente as ligações com os centros de consumo nos Estados Unidos, na Europa e na Âsia que estabelecem fluxos de minérios por grandes distâncias; na região, as minas localizam-se a centenas de quilômetros dos portos ou dos distritos industriais, e o transporte do minério requer o uso de hidrovias, ferrovias, rodovias e dutos em sistemas multimodais, que ligam as áreas de extração aos locais onde se realiza a exportação e/ou a transformação industrial do minério (Figura 2).

A conexão logística entre as áreas das minas e as dos portos foi viabilizada, basicamente, pelos modais ferroviário, hidroviário e dutoviário, com importância crescente do modal rodoviário a partir dos anos 1990, como reflexo da expansão dos corredores. As hidrovias e as ferrovias foram adotadas para transportar grandes volumes de minérios em granéis sólidos, geralmente em percursos superiores a $100 \mathrm{~km}$. A conformação logística ferroviária, especificamente, é a que envolve mais investimentos; todavia, pode potencializar a diversificação das atividades econômicas em função da possibilidade do surgimento de terminais intermediários, abrindo a oportunidade para que, nos locais situados no trajeto entre o porto e as minas, surjam novas atividades econômicas e também haja a expansão do corredor por meio de novos ramais ferroviários ou estradas de rodagem.

Nas áreas das minas, independentemente da estrutura logística adotada, são realizados tão somente a lavra e o beneficiamento primário dos minérios. Por isso, nelas, a possibilidade de surgimento de novas atividades econômicas limita-se ao adensamento da prestação de serviços à

exemplos, demonstrando como a localização das minas e dos complexos geográficos (distritos siderúrgicos) que se formavam a partir delas tinha dependência estreita da proximidade dos centros consumidores e das fontes de energia, além da capacidade e do custo dos transportes. Bunker $(1985,2007)$ elucida que os avanços nas técnicas de extração e beneficiamento de minérios, de geração e transmissão de energia, e nos meios de transporte permitiram reorientar as logísticas e as geografias associadas à mineração industrial, possibilitando a valorização de minas cada vez mais distantes daqueles centros. Para mais detalhes sobre os aspectos geográficos da mineração, consultar também Spooner (1981). 
mineradora. Nesses casos, a expansão populacional vincula-se à atração exercida pelos empregos gerados por essas atividades, principalmente nas fases de implantação e expansão de infraestruturas. Já na outra extremidade do corredor, há uma tendência para a expansão de atividades portuárias e a possibilidade de surgimento de unidades de transformação industrial.

A valorização de recursos minerais na fronteira e sua incorporação em termos físicos à produção planetária de mercadorias ensejaram, assim, a consolidação, na última metade do século $\mathrm{XX}$, de quatro corredores de exportação na Amazônia oriental brasileira (Figura 2).

O mais antigo desses corredores, chamado aqui de "corredor 1", foi o estabelecido em torno da Estrada de Ferro Amapá (EFA) e da BR-210, um eixo rodoferroviário E-W e N-S com cerca de $194 \mathrm{~km}$ entre a serra do Navio (minas) e Santana (porto), situado no centro-leste do Amapá (Figura 2). Esse eixo surgiu nos anos 1950 em função da extração, pela Indústria e Comércio de Minérios S.A. (ICOMI), do manganês da serra do Navio, considerado exaurido em fins dos anos 1990. Esse empreendimento, motivado pela demanda estratégica de manganês pelos Estados Unidos, teve consequências diretas sobre a geografia dessa porção da Amazônia oriental, ao mesmo tempo que a ligação entre as minas e o porto exportador uniu, por via terrestre, o interior do Amapá à zona costeira do estado. Essa região interior também foi impactada pela implantação de minas de caulim, no corredor 2 , o que será discutido mais adiante.

$\mathrm{Na}$ atual década (2010), esse corredor tem retomado seu dinamismo, com empresas de pequeno ou médio porte que atuam na extração de ouro, ferro, cromo e outros minerais (Oliveira, 2010). A maior parte das novas minas liga-se à EFA por meio de rodovias.

Nos anos 1970 e 1980, foram estabelecidos, no âmbito das políticas federais dos governos militares, sobretudo do Programa de Polos Agropecuários e Agrominerais da Amazônia (Polamazônia) e do Programa Grande Carajás (PGC), o corredor 2, constituído pela hidrovia dos rios Trombetas, Amazonas e Pará, e o corredor 3, da Estrada de Ferro Carajás (EFC). As ações que resultaram na formação dos corredores 2 e 3 foram concebidas pelo planejamento oficial do espaço amazônico durante os governos militares (1964-1985) como interligação entre "polos de desenvolvimento", o que denota, contraditoriamente, o papel e a importância da logística na consolidação de corredores, e não dos polos. 


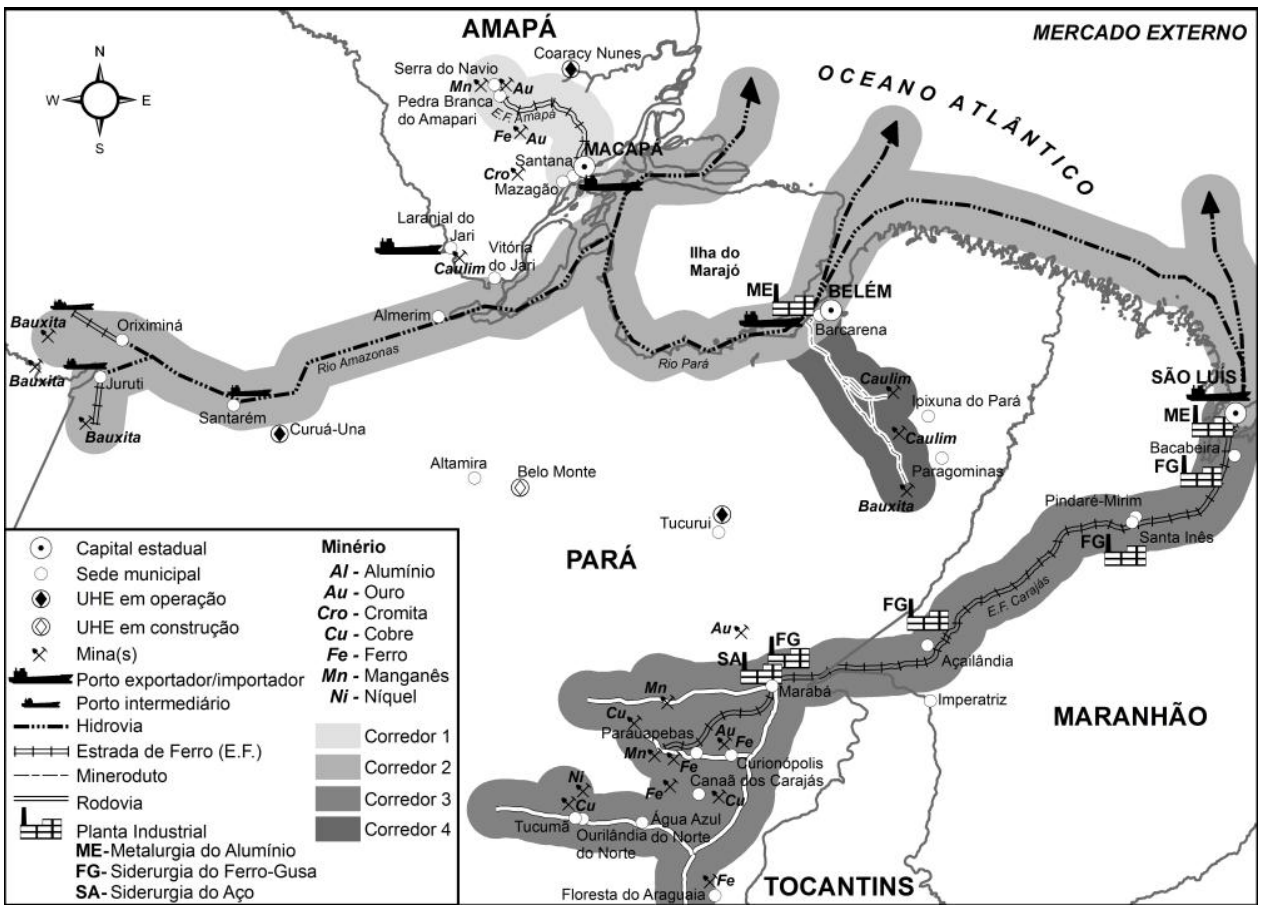

Figura 2: Corredores de exportação de commodities minerais na Amazônia oriental brasileira e estrutura logística.

Fonte: Elaboração dos autores.

O corredor 2 situa-se nas porções norte e nordeste do Pará, ligandose depois ao centro-norte do estado do Maranhão. Ele articula as áreas das minas de bauxita da Mineração Rio do Norte (MRN), em Oriximiná (vale do rio Trombetas), e da Alcoa, em Juruti, com os distritos industriais ou portos exportadores de Barcarena (Vila do Conde) (PA) e São Luís (MA), onde se localizam as plantas da Alunorte (alumina), da Albrás (alumínio) e da Alumar (alumina e alumínio), respectivamente. A distância aproximada entre Oriximiná e Barcarena é de 760km, e entre Juruti e São Luís é de $1400 \mathrm{~km}$. Trata-se de um eixo hidroviário E-W dinamizado pela cadeia mundial do alumínio, cujos empreendimentos na região datam de diferentes épocas, entre 1970 e 2000. 
De modo secundário, é realizada no corredor 2 a mineração de caulim pela Cadam S.A. em Vitória do Jari (AP), com planta de beneficiamento em Almeirim (PA) e ligação por um pequeno mineroduto ( $3 \mathrm{~km}$ de extensão), para posterior exportação pelos rios Jari e Amazonas.

O corredor 3 localiza-se inicialmente nos estados do Pará e do Maranhão. A Estrada de Ferro Carajás (EFC), com disposição SW-NE e cerca de $890 \mathrm{~km}$ de extensão, cruza parte do Sudeste Paraense, da PréAmazônia e da Baixada Maranhense até chegar à Região Metropolitana de São Luís (RMSL), onde se localiza o porto de Itaqui. O corredor foi dinamizado pela valorização dos abundantes depósitos da serra de Carajás e de seu entorno, que abrigam minas de ferro, ouro, manganês, níquel e cobre. Tal como no corredor 2, a explotação e a transformação industrial de minérios, impulsionadas pelo governo federal, tiveram, explicitamente, o objetivo de gerar divisas para o incremento da balança externa brasileira (Valverde, 1989; Monteiro, 2005).

A Companhia Vale do Rio Doce (CVRD) é a principal empresa mineradora do corredor 3 e, desde os anos 1980, tem intensificado a mercantilização de minerais da região, seja por meio de novos projetos, seja pela ampliação dos já existentes. Em Marabá (PA), Açailândia (MA), Pindaré-Mirim (MA) e Bacabal (MA), foram implantadas, em diversos momentos, siderúrgicas independentes que valorizam o minério de ferro extraído em Carajás mediante a produção de ferro-gusa. Uma mudança importante ocorreu em 1996 com a privatização da CVRD, que, como empresa privada, adotou, em 2007, o nome fantasia de "Vale".

O corredor 4 é o de formação mais recente, dos anos 1990, quando teve início a extração de caulim no vale do rio Capim, em Ipixuna do Pará (Nordeste do estado), pela Imerys Rio Capim Caulim (IRCC) e pela Pará Pigmentos S.A. (PPSA). O modal adotado foi o dutoviário (mineroduto), implantado com sentido SE-NW até chegar ao distrito industrial e porto de Vila do Conde, em Barcarena (PA), situado a mais de $200 \mathrm{~km}$ das minas. $\mathrm{Na}$ década de 2000, o corredor foi expandido com a inauguração do projeto de extração de bauxita da CVRD em Paragominas (PA), que também escoa o minério por um duto (Figura 2).

As cidades de Barcarena (PA) e São Luís (MA) são pontos extremos (distritos portuários e industriais) de dois corredores de exportação, 2 e 4 , no primeiro caso, e 2 e 3, no segundo. Para fins de análise, Barcarena está sendo considerada no corredor 2 devido à sua maior ligação com a "tradicional" sub-região do Baixo Tocantins. São Luís, por sua vez, será considerada no corredor 3, dada a continuidade mais forte que mantém com a Estrada de Ferro Carajás (EFC) (Figura 2). 
Além disso, está-se considerando cidades que, apesar de não serem cortadas por eixos de exportação, sofreram os impactos indiretos da implantação de portos e distritos industriais, caso de Abaetetuba (PA), na área de influência de Vila do Conde (Barcarena), e dos municípios que integram a Região Metropolitana de São Luís (RMSL).

As empresas do corredor 4, assim como a Alcoa (corredor 2), as que a CVRD criou após 1990 para viabilizar projetos de extração mineral em Carajás (corredor 3) e as que se sucedem à Icomi no Amapá (corredor 1), surgiram em outro contexto da mineração industrial na Amazônia, quando a ação do Estado no planejamento do espaço passou a ser menos efetiva. Ainda assim, nos programas do governo federal para a região, os corredores em análise constam como eixos prioritários para a atração de investimentos privados e a alocação de investimentos públicos na dotação de infraestruturas (portos, rodovias, hidrelétricas, hidrovias etc.). Mantevese, dessa maneira, a característica básica dos eixos de exportação, com ênfase na mineração industrial (Coelho, Monteiro e Santos, 2004).

A formação desses corredores de exportação provocou importantes mudanças geográficas na Amazônia oriental brasileira, em decorrência da adoção de novos modos de valorização de minérios que se associam a frentes de recursos da fronteira contemporânea. Sua estruturação, como se indicou, já ultrapassa décadas e, contemporaneamente, passa a dar lugar a geografias mais estáveis.

\section{Corredores de exportação e suas repercussões em dinâmicas urbanas}

A estruturação dos corredores de exportação permitiu a incorporação de espaços da fronteira amazônica à economia-mundo, com dinâmicas relacionadas a frentes de recursos (mercantilização de minérios), o que impulsionou mudanças e permanências, tanto em termos demográficos quanto em termos hierárquicos nas cidades abarcadas por esses corredores. A seguir, é feita a análise das configurações urbano-regionais ao longo dos corredores, tomando-se por base a divisão do espaço em sub-regiões, a criação de cidades, seu tamanho e sua hierarquia na rede urbana.

\footnotetext{
${ }^{5}$ Não estão sendo consideradas, portanto, as dinâmicas intraurbanas e as configurações urbanas locais, que envolvem a criação de company towns e o crescimento de povoados, vilas ou cidades por meio de diversos tipos de assentamentos (formais e informais) no entorno de empreendimentos vinculados à mineração industrial. Ambos os casos estão na
} 
O ano de 1970 serve como indicativo para o início das mudanças, ainda que o corredor 1 tenha se formado anteriormente, nos anos 1950. O número de cidades era maior, ou esse número pouco variou ao longo do tempo (de 1970 a 2010), nas sub-regiões mais "tradicionais" que viriam a ser abarcadas pelos corredores. Nesse cenário, a menor influência das frentes de recursos ${ }^{6}$ sobre a criação de cidades expressa uma ocupação mais antiga, de idade secular, e a existência de estruturas políticas já consolidadas nas épocas de implantação de empreendimentos destinados à valorização de produtos minerais na Zona Costeira do Amapá (corredor 1), no Baixo Amazonas (corredor 2), no Baixo Tocantins (corredor 2), na Baixada Maranhense (corredor 3) e na ilha de São Luís (corredor 3) (Figura 3).

Quanto ao corredor 2, embora o processo de criação de cidades tenha sido pouco intenso, ele merece atenção pela vinculação direta com a mineração industrial. Das seis novas urbes, duas (Terra Santa e Curuá) foram criadas no entorno das minas do vale do rio Trombetas (PA) e outras duas, no entorno da mineração de caulim no Amapá (Laranjal e Vitória do Jari). Em relação ao Baixo Amazonas, evidencia-se um impacto de abrangência mais local do que sub-regional, visto que a malha municipal e as relações territoriais predominantes, que se dão no universo ribeirinho, foram pouco alteradas em seu conjunto.

gênese de cidades, a exemplo de Parauapebas (PA), Santana (AP), Laranjal e Vitória do Jari (AP). A este respeito, consultar Trindade Jr. e Rocha (2002) e Autor 2 et al. (2005).

${ }^{6}$ Ainda que o foco do texto recaia sobre as frentes de recursos associadas à mineração industrial, deve-se registrar também a atuação concomitante da garimpagem e da indústria madeireira, que atingiu essas sub-regiões em diversos momentos a partir da década de 1970. Essas atividades permanecem ativas em algumas delas na atual década (2010). O mesmo é válido para as sub-regiões de formação mais recente, não secular, especialmente nos corredores 1, 3 e 4, porém, nesses casos, já se está na fase de formação da fronteira contemporânea (pós-1950). 


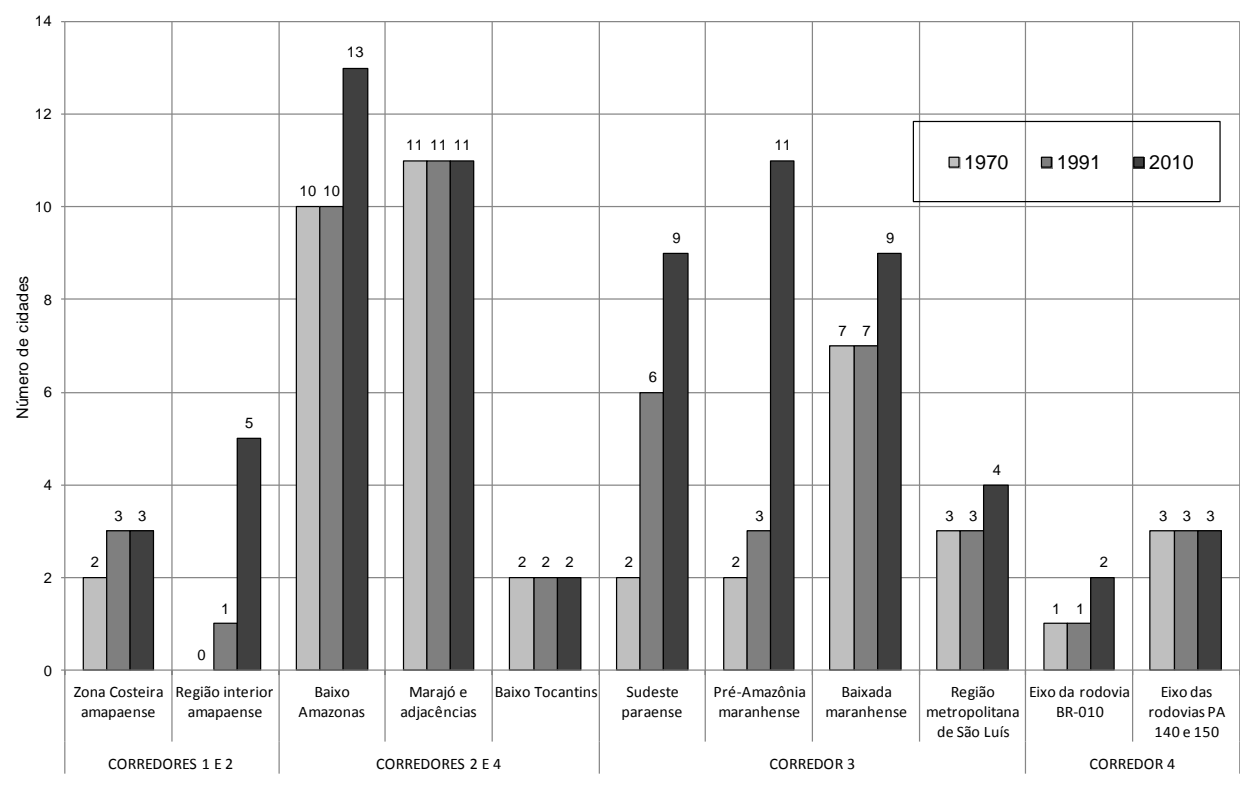

Figura 3: Número de cidades por sub-regiões em 1970, 1991 e 2010.

Fonte: Elaboração dos autores com base em IBGE (1987, 1993, 2008, 2010).

Em relação às demais sub-regiões consideradas "tradicionais", existem outros aspectos importantes. No Marajó, onde não foram implantadas infraestruturas de extração, transformação industrial, embarque ou geração de energia, não houve alteração no número de cidades a partir de 1970, até mesmo pelo fato de esse espaço ter sido um dos menos impactados pela fronteira amazônica contemporânea. O Baixo Tocantins, ao contrário, foi fortemente impactado em sua organização socioespacial e socioambiental (Trindade Júnior e Rocha, 2002), sem que tenha havido a criação de novas cidades, inclusive nas áreas direta ou indiretamente influenciadas pela mineração. ${ }^{7}$ Situação parecida é a da ilha de São Luís, onde foi criada apenas uma cidade (Raposa), porém o impacto das mudanças resultantes da implantação de distritos portuário-industriais (Itaqui e Ponta da Madeira) foi tão intenso que converteu esse espaço numa região metropolitana.

\footnotetext{
${ }^{7}$ No Médio Tocantins, onde foi implantada a Usina Hidroelétrica de Tucuruí, a criação de municípios foi mais significativa. Contudo, ao contrário do Baixo Tocantins, essa área era menos ocupada e foi impactada diretamente pela abertura da rodovia Transamazônica na década de 1970, eixo de central importância nas mudanças geográficas recentes da Amazônia brasileira (Tavares, 1993).
} 
Após 1970, o processo de criação de cidades foi mais intenso em algumas áreas do corredor 1, especificamente no interior do Amapá, e do corredor 3, incluindo o Sudeste Paraense e a Pré-Amazônia maranhense (Figura 3). No corredor 1, houve a criação de quatro cidades (Santana, Serra do Navio, Pedra Branca do Amapari e Porto Grande), como reflexo das novas ocupações na área de entorno das minas de serra do Navio da EFA e do porto de Santana. No contexto desta sub-região surgiram também as novas cidades no entorno das minas e do porto da Cadam (corredor 2).

Ao contrário das sub-regiões discutidas anteriormente, essa subregião era, até meados das décadas de 1950 e 1960, um espaço pouco ocupado, o que favoreceu as mudanças e a fragmentação política do território. No Sudeste Paraense, Parauapebas foi criada em 1989, após o início da extração de ferro na serra dos Carajás. Na Pré-Amazônia maranhense, Açailândia surgiu como cidade em 1981, tornando-se um polo de siderurgia primária. As demais cidades têm sua gênese ligada tanto ao avanço de outras frentes de recursos (indústria madeireira e garimpagem) quanto a frentes de povoamento, principalmente no Pará e no Maranhão, onde a abertura de rodovias possibilitou a expansão camponesa e a agropecuária capitalística (Coelho, 1997; Tavares, 1992).

No corredor 4, apenas uma cidade foi criada (Ipixuna do Pará) (Figura 3), não obstante a criação de várias outras no entorno, em áreas não impactadas pela mineração industrial e que integram a "velha" fronteira agropecuária da Amazônia oriental (Cardoso, Lima e Barbosa, 2009; Veríssimo et al, 1992). Deve-se ressaltar que esse corredor, além de ser o mais recente, datando dos anos 1990, inaugurou um novo modelo de escoamento de minérios na Amazônia, que se faz por uma rede de minerodutos cujos efeitos socioespaciais são menos visíveis.

O impacto demográfico decorrente da valorização de recursos minerais, ou mesmo de outros fatores, no âmbito dos corredores de exportação, pode ser inferido pelo tamanho populacional das urbes, que se consolidaram no intervalo de 20 a 100 mil habitantes ou menos que isso, com a maior parte delas estando abaixo de 50 mil (Figura 4). Esse quadro ratifica o padrão da rede urbana amazônica, caracterizado pela primazia das metrópoles regionais, por poucos núcleos intermediários e por uma plêiade de pequenas urbes (Corrêa, 1987, 1991; Coelho, 1990, Trindade Júnior, 2006).

A hierarquia urbana ao longo dos corredores também expressa esse padrão (Figura 4, Quadro 1), com sistemas de cidades "tradicionais", "reativadas" ou "novas" (Corrêa, 1987), ligadas às áreas de influência de 
três metrópoles regionais: Belém (PA) (Amapá, Oeste, Nordeste e Sudeste do Pará), Fortaleza (CE) (Maranhão) e Goiânia (GO) (Oeste do Maranhão e Sudeste do Pará) (IBGE, 2008).

No conjunto de cidades diretamente impactadas pela mineração industrial, existem algumas poucas exceções a contingentes populacionais urbanos abaixo de 100 mil. São Luís (MA) e Macapá (AP), ${ }^{8}$ na condição de capitais estaduais e centros regionais antigos dinamizados por eixos e infraestruturas de valorização industrial de minérios, chegaram ao ano de 2010 com cerca de 955 mil e 380 mil habitantes, respectivamente. Outro centro regional antigo reativado, a cidade de Marabá (PA), tinha em 2010 aproximadamente 186 mil pessoas. Por fim, encontram-se Santana (AP) (100 mil habitantes), povoado ribeirinho secular convertido em cidade, e Parauapebas (PA) (138 mil habitantes), que é uma urbe recente, surgida no início dos anos 1980 a partir da fusão de um conjunto residencial homônimo da CVRD com um povoado (Rio Verde).

Com exceção de São Luís, as cidades acima citadas apresentam porte e/ou função de cidades médias. Quando se considera todo o conjunto de cidades com impactos diretos da mineração, nota-se que as maiores possibilidades de crescimento estão vinculadas a fatores outros, como a administração pública, o comércio, os serviços - ligados ou não a atividades portuárias e industriais - e a agropecuária ou, em pulsos mais breves de tempo, as atividades madeireiras (sobretudo em Marabá [PA], Paragominas [PA] e Açailândia [MA]). São, portanto, diversos os fatores, que atuam em múltiplas frentes, sobrepostas no tempo e no espaço.

${ }^{8}$ O Município de Macapá abrigava, até a emancipação de Santana, em 1987, o porto da Icomi. Pela época de implantação desse projeto, a capital amapaense passou por intervenções urbanísticas que modificaram seu espaço intraurbano. Por isso se considera que ela sofreu impactos diretos da mineração industrial. Além disso, Macapá foi articulada ao interior por meio da EFA e de rodovias que contornam serra do Navio, integrando o Amapá no sentido N-S. 

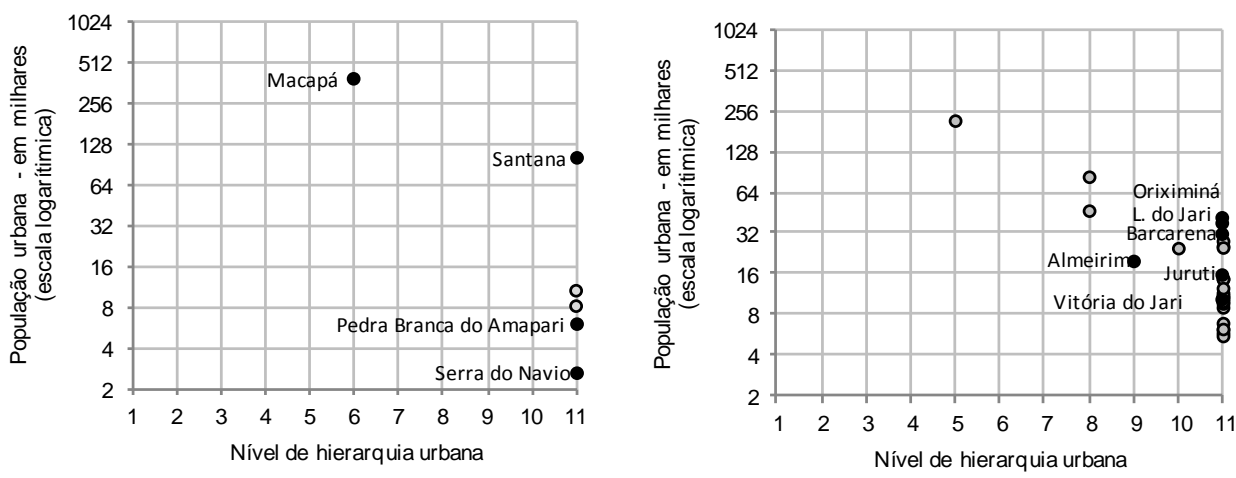

Corredor 3 - 33 cidades
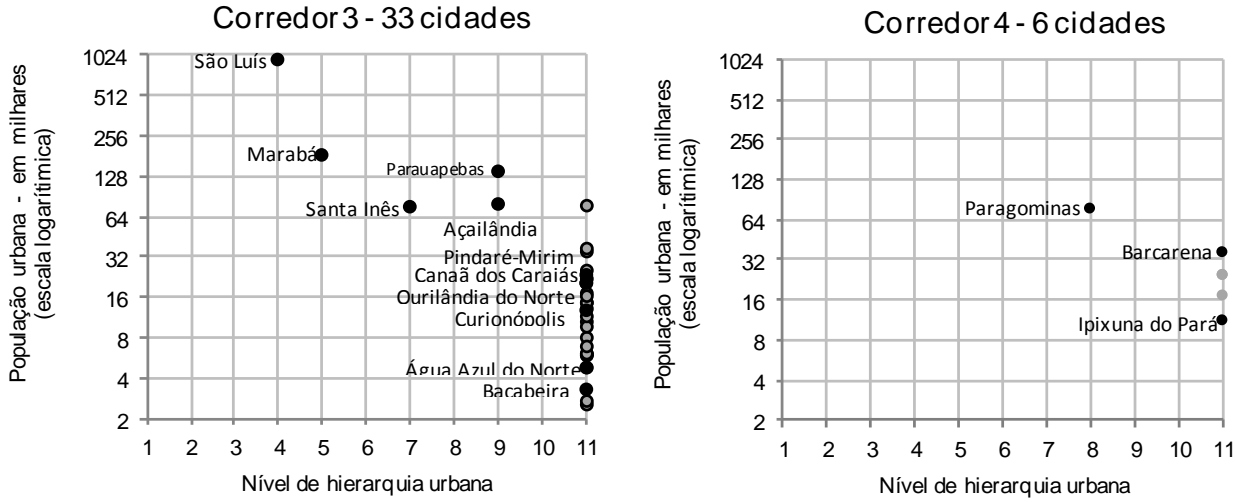

\section{Legenda}

- Cidades diretamente impactadas pela valorização industral de minerais

- Outras cidades dos corredores de exportação

Hierarquia urbana

1 Grande metrópole nacional

2 Metrópole nacional

3 Metrópole regional

4 Capital regional
5 Capital regional B

6 Capital regional $\mathrm{C}$

7 Centro sub-regional $A$

8 Centro sub-regional $B$
9 Centro de zonaA

10 Centro dezonaB

11 Centro local

Figura 4: Hierarquia urbana (2007) e tamanho populacional (2010) das cidades ao Longo dos corredores da exportação na Amazônia oriental brasileira.

Fonte: Elaborado com base em IBGE $(2008,2011)$. 
Dito em outras palavras, o dinamismo urbano tende a ser maior na proporção inversa à dependência em relação a um único empreendimento, tanto mais limitado quando se trata de extração mineral. Neste caso, o crescimento de rendas (em função de impostos, salários temporários, consumo etc.), serviços e população, impulsionado fundamentalmente por rápidas migrações a partir de municípios ou estados vizinhos, é maior na fase de implantação e nos primeiros anos que se seguem ao início ou à expansão de atividades minerárias (Coelho et al, 2005).

A trajetória da população urbana em Parauapebas (PA) ilustra bem essa dinâmica, uma vez que os investimentos crescentes em mineração têm atraído um número cada vez maior de pessoas. Em pouco mais de uma década de fundação, em 1991, a cidade já contava com mais de 27 mil habitantes, registrando-se nessa fase o impacto inicial das obras na serra dos Carajás. Nos dois períodos intercensitários subsequentes, o crescimento foi ainda maior, acompanhando o aumento e a diversificação de investimentos. Entre 1991 e 2000, houve uma variação absoluta de 31,8 mil habitantes e de 79,5 mil entre 2000 e 2010. Ressalta-se que Parauapebas, ao contrário de outras cidades que foram impactadas há mais de uma década por atividades de extração mineral e que possuem baixos contingentes populacionais urbanos (Quadro 1), conta, não apenas com um projeto, mas com vários, implantados pela CVRD desde a década de 1980.

Em Marabá (PA), que conta tanto com empreendimentos de extração quanto de transformação mineral, houve uma variação de 60,7 mil pessoas entre 1980 e 1991, e de 51,7 mil de 2000 até 2010, períodos nos quais foram maiores os investimentos da CVRD na região de Carajás. Além disso, por ser um distrito siderúrgico (dedicado à produção de ferro-gusa e aço) e um polo regional de comércio e serviços, essa cidade tem maior capacidade de atração de pessoas.

Situação particular é a de Santarém (PA) (corredor 2) e Macapá (AP) (corredor 1), ou mesmo de Belém (PA) e Imperatriz (MA), situadas fora do espaço imediato aos corredores de exportação e que, mesmo não sendo diretamente impactadas por atividades destinadas à valorização de recursos minerais, tornaram-se para elas um ponto de apoio, o que contribuiu para aumentar a centralidade urbana em suas respectivas áreas de influência. $\mathrm{Na}$ ponta do corredor 3 , a formação de um complexo portuário-industrial foi decisiva, conforme já foi dito, para o processo de metropolização de São Luís (MA), enquanto, no corredor 4, o advento da mineração industrial é um fator a mais para o aumento da importância de Paragominas (PA) em âmbito sub-regional (Quadro 1). 


\begin{tabular}{|c|c|c|c|c|}
\hline Municípios & $\begin{array}{l}\text { Hierarquia } \\
\text { urbana em 1987 } \\
\text { (revisão de 1977) }\end{array}$ & $\begin{array}{l}\text { Hierarquia } \\
\text { urbana em } 1993\end{array}$ & $\begin{array}{l}\text { Hierarquia urbana } \\
\text { em } 2007\end{array}$ & $\begin{array}{l}\text { População } \\
\text { urbana em } \\
2010 \text { (hab.) }\end{array}$ \\
\hline \multicolumn{5}{|c|}{ Cidades impactadas até a década de 80} \\
\hline Macapá (AP) & Capital regional & $\begin{array}{l}\text { Centro sub- } \\
\text { regional }\end{array}$ & Capital regional C & 380.937 \\
\hline Santana (AP) & N.A. & Centro de zona & Centro local & 99.094 \\
\hline Serra do Navio (AP) & N.A. & N.A. & Centro local & 2.575 \\
\hline Oriximiná (PA) & Centro de zona & Centro de zona & Centro local & 40.182 \\
\hline Almeirim (PA) & Centro local & Centro local & Centro de zona & 19.972 \\
\hline Lar. do Jari (AP) & N.A. & Centro de zona & Centro local & 37.824 \\
\hline Vitória do Jari (AP) & N.A. & N.A. & Centro local & 10.318 \\
\hline \multicolumn{5}{|c|}{ Cidades impactadas na década de 1980} \\
\hline Barcarena (PA) & Centro local & Centro local & Centro local & 36.357 \\
\hline Marabá (PA) & Centro de zona & C. sub-regional & Capital regional & 186.122 \\
\hline Parauapebas (PA) & N.A. & Centro de zona & Centro de zona & 138.769 \\
\hline Açailândia (MA) & N.A. & Centro local & Centro de zona & 78.241 \\
\hline São Luís (MA) & $\begin{array}{l}\text { Centro } \\
\text { submetropolitano }\end{array}$ & $\begin{array}{l}\text { Metrópole } \\
\text { regional }\end{array}$ & Capital regional & 955.600 \\
\hline
\end{tabular}

Cidades impactadas nas décadas de 1990 e 2000

\begin{tabular}{|c|c|c|c|c|}
\hline $\begin{array}{ll}\text { Pedra Branca } & \text { do } \\
\text { Amapari (AP) } & \end{array}$ & N.A. & N.A. & Centro local & 5.970 \\
\hline Mazagão (AP) & Centro local & Centro local & Centro local & 8.280 \\
\hline Juruti (PA) & Centro local & Centro local & Centro local & 15.843 \\
\hline Ipixuna do Pará & N.A. & Centro local & Centro local & 12.228 \\
\hline Paragominas (PA) & Centro de zona & Centro de zona & $\begin{array}{l}\text { Centro sub- } \\
\text { regional }\end{array}$ & 76.478 \\
\hline C. Carajás (PA) & N.A. & Centro local & Centro local & 20.738 \\
\hline Curionópolis (PA) & N.A. & Centro local & Centro local & 12.528 \\
\hline A. A. do Norte (PA) & N.A. & Centro local & Centro local & 4.876 \\
\hline $\begin{array}{l}\text { Ourilândia do Norte } \\
\text { (PA) }\end{array}$ & N.A. & Centro de zona & Centro local & 19.931 \\
\hline
\end{tabular}




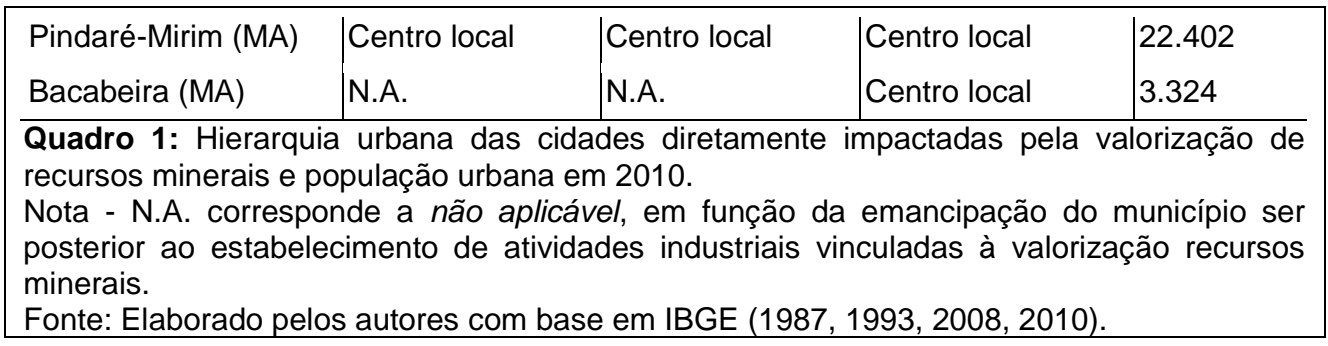

Esses elementos são importantes para o entendimento da hierarquia urbana, apresentada em diferentes momentos pelo Instituto Brasileiro de Geografia e Estatística (IBGE, 1987, 1993, 2008). Nela, os centros locais ocupam o último nível, influenciando somente os espaços municipais ou de um entorno próximo deles. Em comparação com a hierarquia de outras épocas (Quadro 1), observa-se que, nos anos de 1987, 1993 e 2007, as cidades com atividades de valorização de recursos minerais na Amazônia oriental brasileira ocupavam, na maioria dos casos, posição de centros locais, o que demonstra a menor importância histórica e territorial delas na centralidade de relações que configuram as redes urbanas (Figura 4).

Nos corredores em análise, as cidades de pequeno porte com atividades exclusivas de mineração, movimentação portuária ou de indústrias apresentam uma característica particular: além de poucas vezes deixarem de ser centros locais, podem ter a sua importância reduzida com o tempo, a exemplo de Oriximiná (PA) e Santana (AP) (Quadro 1). O caráter instável da mineração como uma frente de recursos, a não consolidação de um setor de comércio e serviços mais dinâmico e a não diversificação da economia podem estar na explicação desse fato. Barcarena (PA), em razão das importantes e crescentes funções portuárias e industriais do distrito de Vila do Conde, destaca-se no conjunto das pequenas cidades, porém, devido à sua proximidade de Belém, sendo incorporada, na condição de centro local, à região metropolitana da capital paraense, situação que, em termos de dinâmica urbana, é semelhante à de Santana em relação a Macapá (PA).

$\mathrm{O}$ corredor 3, da EFC, foi o único em que se estabeleceram, de fato, articulações mais fortes entre distintos sistemas urbano-regionais perpendiculares ao eixo da ferrovia, que cruza o Sudeste Paraense, a PréAmazônia e a Baixada Maranhense, chegando até a Região Metropolitana de São Luís (RMSL).

Nesse sentido, a ferrovia mostra-se como o fator mais favorável à promoção daquelas articulações e ao surgimento de novas centralidades, 
sobretudo quando apresenta pontos intermediários, com implantação de atividades industriais, ou se liga a outros eixos dinamizados por rodovias e hidrovias. A EFC, se não chegou a formar um novo eixo urbano-regional, contribuiu, pelas relações estabelecidas por processos industriais e na circulação de pessoas e mercadorias, para a consolidação da área de influência de São Luís (MA) e de Marabá (PA). Além disso, contribuiu também para a criação de centralidades em Açailândia (MA) - como centro industrial e de serviços - e Parauapebas (PA) - muito próxima de Marabá em população (Quadro 1) e que se consolida no papel de centro articulador entre as pequenas cidades da região de Carajás (Quadro 1). No corredor 1, a EFA, apesar de menos complexa em suas relações com o território, expandiu a influência de Macapá para o interior do território.

Nos corredores 1, 2 e 4, onde a ocupação, antes do advento da mineração industrial, era mais consolidada que no corredor 3, assistiu-se, seja por efeito dessa atividade, seja por outros fatores que intervieram na formação da fronteira contemporânea na região amazônica, ao fortalecimento das principais centralidades urbanas já existentes (Figura 4), com Macapá (AP) na zona costeira e no interior do estado do Amapá, Santarém (PA) no Baixo Amazonas, Breves (PA) no Marajó, Abaetetuba (PA) no Baixo Tocantins e Paragominas (PA) no eixo da BR-010. Ao reforçar a centralidade dessas cidades, a mineração industrial contribui decisivamente para manter a configuração urbano-regional de determinadas porções da Amazônia oriental brasileira.

\section{Considerações finais}

Na última metade do século passado, a crescente demanda planetária por commodities minerais, impulsionada por determinações sistêmicas da economia-mundo, esteve na gênese de mudanças espaciais derivadas da expansão de frentes de recursos no âmbito da fronteira amazônica. Nesse contexto, o interesse de empresas mineradoras esteve associado a ações do Estado nacional brasileiro, conduzindo investimentos para a extração e a transformação mineral de grande escala, com produção voltada quase que integralmente para o mercado externo. Disso resultou a crescente valorização de recursos minerais na porção oriental da Amazônia brasileira, o que exigiu a interligação entre minas, distritos industriais e portos por meio de logísticas e infraestruturas muito eficientes. A organização desses aparatos técnicos consolidou corredores de exportação na região. 
Mais de meio século depois do estabelecimento do primeiro desses eixos - e considerando-se a interação que há entre as diversas escalas -, constata-se que os impactos mais relevantes ocasionados diretamente pela mineração industrial circunscrevem-se aos municípios nos quais foram implantadas minas, portos e distritos industriais. Ou seja, as principais alterações espaciais concentram-se nos extremos dos corredores de exportação. Essa consideração traz, para a análise, a importância de outros fatores, como a garimpagem, a indústria madeireira, a agropecuária, o comércio e os serviços no conjunto de mutações geográficas recentes na Amazônia oriental.

Nos locais ou em áreas próximas às minas, aos portos e aos distritos industriais, houve a criação de novas cidades, por efeito de fragmentações territoriais e de migrações rápidas, sobretudo como efeito local ou subregional das mudanças, o que depende também, e fundamentalmente, das espacialidades e territorialidades preexistentes, conferindo particularidades a cada corredor. Assim, as mudanças e os impactos mais drásticos ocorreram em sub-regiões de formação recente, menos densamente ocupadas e com sociedade civil mais frágil à época da implantação de empreendimentos de extração ou de transformação mineral, especialmente o interior do estado do Amapá, o Sudeste Paraense e a Pré-Amazônia maranhense. Nessas duas últimas sub-regiões, a expansão da agropecuária e da indústria madeireira, além de alguns surtos de garimpagem, contribuiu, igualmente, para desencadear mudanças.

Esses corredores de exportação cruzam regiões dos estados do Amapá, do Pará e do Maranhão e abrangem 73 municípios, sem, contudo, terem alterado de modo significativo a rede urbana, dado, na maior parte das situações, o reforço às centralidades urbanas já existentes e às disparidades entre as urbes no que diz respeito à população e à posição na hierarquia urbana, aspecto que necessita de estudo mais detalhado. Apenas no corredor da Estrada de Ferro Carajás (EFC) houve, de fato, maior impacto sobre as articulações urbano-regionais, na medida em que novas centralidades foram criadas (Açailândia e Parauapebas), ao mesmo tempo que distintas áreas de influência de cidades mais antigas foram conectadas e consolidadas (São Luís e Marabá).

Assim, a articulação entre demandas planetárias por insumos, interesses dominantes em termos nacionais e as frentes de recursos da fronteira condicionou a estruturação dos corredores de exportação e as espacialidades a eles associadas. Essas espacialidades, por sua vez, relacionam-se dialeticamente com pelo menos dois outros padrões mais gerais que permitem, analiticamente, contextualizar as mudanças espaciais 
na região: um padrão espacial, vinculado a frentes de recursos da fronteira, que se liga à mercantilização de recursos minerais e florestais; e outro, decorrente das frentes de povoamento pela agropecuária. São, por conseguinte, esses padrões, integrantes da lógica de fronteira, que permitem situar analiticamente as principais mudanças espaciais pelas quais passou a Amazônia oriental na última metade do século XX.

A mineração industrial, especificamente, corrobora as lógicas das frentes de recursos - instáveis populacional e economicamente -, de modo que, apesar de muito significativas em termos de alterações socioespaciais e socioambientais locais, são menos efetivas na escala sub-regional, na qual outros fatores do passado ou do presente tornam-se mais relevantes geograficamente. Verificam-se, portanto, marcas da valorização de recursos minerais na organização espacial de uma região de fronteira, que se aprofundam ou se reproduzem à medida que aumenta a demanda planetária por commodities minerais.

\section{FRONTEIRA, CORREDORES DE EXPORTAÇÃO E REDE URBANA NA AMAZÔNIA ORIENTAL BRASILEIRA}

Resumo: Este artigo analisa a importância dos corredores de exportação nas mudanças e reconfigurações urbano-regionais na segunda metade do século XX na Amazônia oriental brasileira. Apoiado na noção de fronteira, o artigo indica que, espacial e temporalmente, os corredores integram frentes de recursos da fronteira amazônica contemporânea, articuladas à crescente demanda planetária por commodities minerais e à geração de superávits na balança comercial brasileira. O artigo evidencia que a valorização de recursos minerais na região requereu a interligação entre minas, distritos industriais e portos por meio de logísticas, rotas e infraestruturas que consolidaram corredores de exportação. Por fim, demonstra que as principais alterações urbanas decorrentes dos corredores de exportação concentram-se nos seus extremos e que eles, dialeticamente, reforçaram as centralidades urbanas e as disparidades já existentes entre as urbes.

Palavras-chave: Amazônia; fronteira; mineração; corredores de exportação; rede urbana.

FRONTIER, EXPORT CORRIDORS AND URBAN NETWORKS IN THE EASTERN BRAZILIAN AMAZON FRONTIER 
Abstract: This article examines the important role of export corridors in the eastern Brazilian Amazon in influencing urban-regional changes and reconfigurations in the second half of the twentieth century. Employing the concept of the frontier, the present article documents that the corridors spatially and temporally integrated resources from the contemporary Amazon frontier with the growing global demand for mineral commodities that generated Brazilian trade surpluses. The article demonstrates that the recovery of the region's mineral resources required interconnections between mines, industrial districts, and ports through the logistics, routes, and infrastructure consolidated within the export corridors. Finally, the major urban changes that resulted from the export corridors, which were concentrated in their extremes, dialectically reinforced the previously existing urban centralities and disparities in those metropolises.

Key words: Eastern Brazilian Amazon; frontier; mining; export corridors; urban networks.

\section{BIBLIOGRAFIA}

ALBION, R. G (1926). Forests and Sea Power: The Timber Problem of the Royal Navy, 1652-1862. Cambridge: Harvard University Press. 485 p. BADIE, B (1995). La fin des territoires: essai sur desordre international et sur l'utilite sociale du respect. Paris: Fayard. 276 p.

BAHRAM, B.; BUNKER, S. G.; O'HEARN, D. (eds.) (1994). States, Firms, and Raw Materials: The World Economy and Ecology of

Aluminum. Madison: Massachusetts University Press. 321 p.

BEBBINGTON, A.; HINOJOSA, L.; BEBBINGTON, D. H.; BURNEO, M. L.; WARNAARS, X (Nov. 2008). Contention and Ambiguity: Mining and the Possibilities of Development. Development and Change, MaldenMassachusetts, v. 39, n. 6, p. 965-992. DOI: 10.1111/j.14677660.2008.00517.x

BECKER, B. K (1982). Geopolítica da Amazônia. Rio de Janeiro: Zahar. $233 \mathrm{p}$.

(1990). Amazônia. São Paulo: Ática. 92 p.

(2004). Amazônia: geopolítica na virada do III milênio. Rio de Janeiro: Garamond. $172 \mathrm{p}$.

BOMSEL, O.; MARQUES, I.; NDIAYE, D.; SÁ, P. D (1990). Mining and metallurgy investment in the Third World: The end of large projects? Paris: Development Centre and OECD. 221 p. 
BOSSON, R.; BENSON, V (1977). The mining industry and the development. Oxford: Oxford University Press. 304 p.

BRASIL. Ministério do desenvolvimento, indústria e comércio exterior. Alice web 2. Disponivel em:〈http://aliceweb2.mdic.gov.br/index/home〉. Acesso em: 17 nov. 2011.

BRIDGE, G (Nov. 2004). Contested Terrain: Mining and the Environment. Annual Review of Environment and Resources, v. 29, p. 205-259. DOI: 10.1146/annurev.energy.28.011503.163434

BROWDER, J. O.; GODFREY, B. J (1997). Rainforest Cities: Urbanization, Development and Globalization of the Brazilian Amazon. New York: Columbia University Press. 429 p.

BRUNHES, J (1920). La géographie humaine: les faits essentiels groupés et classés, principes et exemples, Tome I. 3e édition. Paris: Librairie Félix Alcan, 1925. 574 p. Première édition.

BRYANT, R.; BAILEY, S (1997). Third World Political Ecology. New York: Routledge. 237 p.

BUNKER, S (1985). Underdeveloping the Amazon. Chicago: The University Chicago Press, 1985. 279 p.

(dez. 2004). Os fatores espaciais e materiais da produção e os

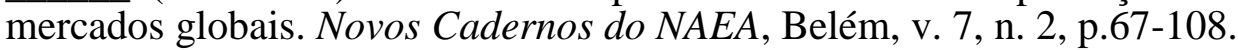

CARDOSO, A. C. D.; LIMA, J. J. F.; BARBOSA, E. J. S (2009). Espaços urbanos. In: MONTEIRO, M. A.; COELHO, M. C. N.; BARBOSA, E. J. S. Atlas Socioambiental: Municípios de Tomé-Açu, Aurora do Pará, Ipixuna do Pará, Paragominas e Ulianópolis. Belém: NAEA/UFPA, p. 303391.

CLARK, A. L.; CLARK, J. C (Set. 1999). The new reality of mineral development: social and cultural issues in Asia and Pacific nations. Resources Policy, v. 25, n. 3, p. 189-196.

CLEARY, D (May. 1993). After the Frontier: Problems with Political Economy in the Modern Brazilian Amazon. Journal of Latin American Studies, v. 25, n. 2, p. 331-349. DOI:10.1017/S0022216X00004685

COELHO, M. C (1997). A polêmica ocupação dos sem-terra na região de Carajás. In: XIMENES, T. (org.). Perspectivas do desenvolvimento sustentável: uma contribuição para a Amazônia 21. Belém: NAEA/UFPA, p. 495-530.

COELHO, M. C. N.; MONTEIRO, M. A.; SANTOS, I. C (jun. 2004). Políticas públicas, corredores de exportação, modernização portuária, 
industrialização e impactos territoriais e ambientais no município de Barcarena, Pará. Novos Cadernos NAEA, Belém, v. 11, n. 1, p. 141-178.

COELHO, M. C.; MONTEIRO, M. A.; LOPES, A. G; LIRA, S. B (dez. 2005). Regiões do entorno dos projetos de extração e transformação mineral na Amazônia Oriental. Novos Cadernos NAEA, Belém, v. 8, n. 2, p. 73-107.

COELHO, M. S. A (abr-jun. 1990). Análise das redes urbanas nordestinas. Revista Brasileira de Geografia, Rio de Janeiro, n. 2, p. 59-74.

CORRÊA, R. L (jul-set. 1987). A periodização da rede urbana da Amazônia. Revista Brasileira de Geografia, Rio de Janeiro, n. 3, p. 39-68.

(1991). A organização urbana. In: Geografia do Brasil: Região norte. Rio de Janeiro: Fundação Instituto Brasileiro de Geografia e Estatística, Diretoria de Geociências, v. 1, p. 255-299.

COSTA, F. A (1993). Grande capital e agricultura na Amazônia. 1. ed. Belém: EDUFPA. 163 p.

COURLET, C (1996). Globalização e fronteiras. Ensaios FEE, Porto Alegre, v. 17, n. 1, p. 11-22, 1996.

FOWERAKER, J (1981). The Struggle for Land: A Political Economy of the Pioneer Frontier in Brazil from 1930 to the Present Day. Cambridge: Cambridge University Press. 290 p.

FURTADO, C (1976). A economia latino-americana. São Paulo: Editora Nacional. 339 p.

GIRAUD, P (1983). Géopolitique des ressources minières. Paris: Economica. $750 \mathrm{p}$.

GODFREY, B. J (1979).. A Road to the Xingu: frontier settlement in southern Pará, Brazil. Dissertação (mestrado). University of California, Berkeley. 243 p.

(1982). Xingu Junction: Rural Migration and Land Conflict in the Brazilian Amazon. Proceedings of the Pacific Coast Council on Latin American Studies, n. 9, p. 71-81.

(Apr. 1990). Boom Towns of the Amazon. The Geographical Review, v. 80, n. 2, p. 103-117.

HÉBETTE, J (2004). Cruzando a fronteira: 30 anos de estudo do campesinato na Amazônia. Belém: EDUFPA.

HÉBETTE, J.; ACEVEDO MARIN, R (1979). Colonização para quem? Belém: NAEA/UFPA.

INNIS, H. A (1933). Problems of Staple Production in Canada. Toronto: Ryerson Press. 
INSTITUTO BRASILEIRO DE GEOGRAFIA E ESTATÍSTICA (1987). Regiões de influência das cidades: revisão atualizada do estudo "Divisão do Brasil em Regiões Funcionais Urbanas". Rio de Janeiro.

IBGE.

(1993). Regiões de influência das cidades: 1993. Rio de Janeiro:

(2008). Regiões de influência das cidades: 2007. Rio de Janeiro.

(2010). Censos demográficos: 1970, 1980, 1991, 2000 e 2010. Disponível em: <http://www.ibge.gov.br/home/>. Acesso em: $15 \mathrm{dez}$.

MACHADO, L. O (1999). Urbanização e mercado de trabalho na Amazônia Brasileira. Cadernos IPPUR, Rio de Janeiro, v. 13, n. 1, p. 109138.

MARTINS, J. S (1975). Capitalismo e tradicionalismo: estudos sobre as contradições da sociedade agrária no Brasil. São Paulo: Livraria Pioneira.

(mai. 1996). O tempo da fronteira: retorno à controvérsia sobre o tempo histórico da frente pioneira e da frente de expansão. Tempo Social: Revista de Sociologia da USP, São Paulo, v. 8, n. 1, p. 25-70.

MATHIS, A.; BRITO, D. C.; BRÜSEKE, F. J (1997). Riqueza volátil e mineração de ouro na Amazônia. Belém: CEJUP. 290 p.

MONBEIG, P (1952). Pionniers et planteurs de São Paulo. Paris: Armand Colin. 376 p.

MONTEIRO, M. A (1998). Siderurgia e carvoejamento na Amazônia: drenagem energético-material e pauperização regional. Belém: UFPA. NAEA. $251 \mathrm{p}$.

(jun. 2005). Mineração industrial na Amazônia e suas implicações para o desenvolvimento regional. Novos Cadernos NAEA, Belém, v. 8, n. 1, p. 141-187.

OLIVEIRA, M. J (2010). Diagnóstico do setor mineral do Estado do Amapá. Macapá: IEPA. 148 p.

PEREIRA, J. C. M (2006). A urbanização da Amazônia e o papel das cidades médias na rede urbana regional. In: CARDOSO, A. C. D. (Org.). $O$ rural e o urbano na Amazônia: diferentes olhares. Belém: EDUFPA. p. 2352.

RYDER, R.; BROWN, L. A (2000). Urban Development at Ecuador Amazon Frontier: Boom Towns or Gloom Towns? In: LITHWICK, H.; GRADUS, Y. (Ed.). Developing Frontier Cities: Global Perspectives, Regional Contexts. Dordrecht: Kluwer Academic Publishers. p. 313-343. 
SAWYER, D. R (1984). Frontier Expansion and Retraction in Brazil. In: SCHMINK, M.; WOOD, C. H. (Ed.). Frontier Expansion in Amazonia. Gainesville: University Presses of Florida. p. 180-203.

SCHNEIDER, R. R (1995). Government and the Economy on the Amazon Frontier. Washington D.C.: The International Bank for Reconstruction and Development. $65 \mathrm{p}$.

SOJA, E. W (1989). Postmodern Geographies: The Reassertion of Space in Critical Social Theory. New York: Routledge; Chapman \& Hall. 248 p.

SPOONER, D (1981). Mining and Regional Development. Oxford: Oxford University Press. 64 p.

TAVARES, M. G. C (1992). O Município no Pará: a dinâmica territorial municipal no Pará. Dissertação (Mestrado em Geografia). Universidade Federal do Rio de Janeiro, Rio de Janeiro. 240 p.

THÉRY, H (2002). Novas fronteiras na Amazônia. In: CONGRESO DE LATINOAMERICANISTAS: Cruzando Fronteiras na Amazônia, 3., Amsterdam. Anais... Amsterdam, July 2002, 7 p.

TRINDADE JÚNIOR, S. C (jan.-jun. 2006). Grandes projetos, urbanização do território e metropolização na Amazônia. Terra Livre, São Paulo, v. 26, p. 177-194.

TRINDADE JÚNIOR, S. C.; ROCHA, G. M (2002). Cidade e empresa na Amazônia: uma apresentação do tema. In: (Orgs.). Cidade e empresa na Amazônia: gestão do território e desenvolvimento local. Belém: Paka-Tatu. p. 13-23.

TURNER, F. J (1920). The Frontier in American History. 4th edition. New York: Dover Publications Inc., 1996. 365 p. Originally published in 1920. UHL, C.; VERÍSSIMO, A.; MATTOS, M. M.; BRANDINO, Z.; VIEIRA, I. C. G (Dec. 1991). Social, economic, and ecological consequences of selective logging in an Amazon frontier: the case of Tailândia. Forest Ecology and Management, Amsterdam, v. 46, n. 3-4, p. 243-273.

VALVERDE, O (1989). Grande Carajás: planejamento da destruição. Rio de Janeiro: Forense-Universitária; São Paulo: EDUSP; Brasília: Editora da UnB. 153 p.

VERÍSSIMO, A.; BARRETO, P.; MATTOS, M.; TARIFA, R.; UHL, C (Dec. 1992). Logging impacts and prospects for sustainable forest management in an oriental Amazonian frontier: the case of Paragominas. Forest Ecology and Management, Amsterdam, v. 55, p. 169-199.

WARREN, K. Mineral Resources (1973). New York: John Wiley \& Sons. $272 \mathrm{p}$. 